\title{
The relationship between hospital volume and outcomes of radical prostatectomy: a new perspective on an old story
}

\author{
Marco Paciotti, Vittorio Fasulo, Giovanni Lughezzani \\ Department of Urology, Humanitas Clinical and Research Center IRCCS, Humanitas University, Rozzano, Italy \\ Correspondence to: Vittorio Fasulo, MD; Giovanni Lughezzani, MD. Department of Urology, Humanitas Clinical and Research Center IRCCS, \\ Humanitas University, Rozzano, Italy. Email: vittorio.fasulo@humanitas.it; giovanni.lughezzani@hunimed.eu. \\ Provenance and Peer Review: This article was commissioned and reviewed by the Guest Section Editor, Dr. Xiao Li (Department of Urology, Jiangsu \\ Cancer Hospital \& Jiangsu Institute of Cancer Research \& Affiliated Cancer Hospital of Nanjing Medical University, Nanjing, China). \\ Comment on: Barzi A, Lara PN Jr, Tsao-Wei D, et al. Influence of the facility caseload on the subsequent survival of men with localized prostate cancer \\ undergoing radical prostatectomy. Cancer 2019;125:3853-63.
}

Submitted Dec 18, 2019. Accepted for publication Jan 16, 2020.

doi: $10.21037 / g s .2020 .01 .08$

View this article at: http://dx.doi.org/10.21037/gs.2020.01.08

In the last decades, there has been a significant improvement in the management and treatment of prostate cancer (PCa). The course of both the localized and advanced disease has deeply changed, thanks to the development and widespread of robot-assisted radical prostatectomy (RP), new drugs, and new radio-oncological machines.

The increased complexity of patient management and treatment individualization questioned the need to centralize complex surgical procedures in tertiary care centers in order to optimize healthcare costs and patient outcomes. This issue has already been addressed by Luft et al. in 1979, with the authors demonstrating decreased mortality rates in surgeries performed at high-volume hospitals (1). However, a full agreement on this topic has not been reached yet. Some authors questioned about the connection between caseload and long-term outcomes, while others wondered if hospitals' volume was more relevant than surgeons' experience $(2,3)$.

Barzi et al. recently added a valuable contribution in order to untangle this relevant topic (4). They performed a retrospective analysis on the National Cancer Database (NCDB), focusing their analysis on RP, which is one of the most complex urological procedures and one the most common uro-oncological surgery performed in US (5).

Previous studies investigated many aspects of the volume-outcome relationship after RP. In this context, nononcological outcomes are the ones that have been studied best. Many authors, indeed, pointed out the correlation between higher hospital volume and decreased rate of inhospital complications, perioperative morbidity, length of stay (LOS), late urinary complications, and readmission risk after RP (6). On the other hand, many studies reported that increasing surgeon volume was associated with similar benefits (6).

A few studies examined the impact of hospital and surgeon volume on oncological outcomes after RP. In a retrospective analysis on 12,635 men, Ellison et al. showed that patients treated at lower-volume institutions were at increased risk of subsequent adjuvant therapies (7). Other authors also found an increased rate of salvage therapy associated with lower surgeon volume (8). In addition, higher risk of positive surgical margins has been associated with both lower-volume hospital and surgeon's although data are still controversial (9-12). Other studies looked at the relationship between volume and mortality. Hospitals' volume appeared to be inversely related to operative and in-hospital mortality, both in pre-robotic and robotic era, as well as hospitals' experience had an impact on 30-day mortality after RP (13-16).

However, the most reliable parameter to evaluate the volume-outcome relationship is still being debated. Some data suggested that high procedure-specific volume is the most significant predictor of in-hospital mortality (17). Hospital and surgeon volumes have often been investigated as distinct variables, though they are obviously interconnected. In this context, Barzi et al. added some 
relevant novelties. First, they distinguished between facility annual caseload (FAC) and facility annual surgical caseload (FASC). FAC was calculated from the number of patients with PCa treated each year, regardless the stage or therapy. FASC was calculated from the number of radical prostatectomies performed at a given facility each year. Barzi et al. included for the first time FAC and FASC in the same study, using them as distinct measures of hospitals' volume, and comparing the strength of their association with outcomes after RP. Secondly, the primary outcome took into consideration was overall survival (OS). Specifically, the FAC and FACS variables were used to divide facilities in 4 distinct volume groups (VGs) according to caseloads, using $50^{\text {th }}, 75^{\text {th }}$ and $90^{\text {th }}$ percentile as thresholds. A multivariable regression model was used to analyze OS by VGs with adjustments for other prognostic factors. Interestingly, when VGs were defined on the basis of the facility PCa caseload, the survival benefit conferred by the high-volume facilities was larger than when VGs were constructed by the facility surgical caseload. They also observed that the differences in OS by FAC or FASC VGs were stronger among patients with low or intermediate National Comprehensive Cancer Network (NCCN) risks than those with high NCCN risks. The reason for this finding is unclear. Since high-risk PCa patients are more likely to need other treatments after surgical procedure, we could expect to find the greatest difference between FAC and FASC in that group of patients.

While several studies reported better short-term outcomes at high-volume hospitals, long-term survival outcome was a missing piece in the puzzle of volumeoutcome relationship for PCa (6). This study found an improvement in the 5-year survival for patients with localized PCa who were treated primarily with RP at highvolume centers (4). Specifically, this benefit was significantly higher for patients who were treated at high overall-volume hospitals compared to high surgical-volume hospitals. This finding suggests that the overall caseload of the facility may be more important than the facility's surgical caseload alone.

Previous studies suggested that the importance of surgeon volume could be overestimated, given that most of the high-volume surgeons work in high-volume facilities and therefore take advantages to all the relative benefits. Some authors, investigating outcomes after radical cystectomy, found that hospital volume is independently associated with survival, even when accounting for surgeon volume, but not vice versa (3). Thus, according to these data, surgeon experience is not a significant predictor of mortality.

Barzi et al. took a step forward in that direction. Their results support the idea that surgical act itself is less important than overall management of the patient. Broad structural approach that characterized high-volume facility, regardless of surgical volume, seems to be more important than surgical skills themselves. High-volume hospitals are usually supposed to have better preoperative testing, greater staff volume in terms of nurses, greater availability and higher quality of services, such as diagnostic and interventional radiology. However, while these factors can account for differences in short-term outcomes, they lose importance when looking at long-term survival. Therefore, the reasons under this correlation are not clear, but some hypothesis can be made. For example, the management of an oncological patient requires a multidisciplinary team: patients treated at large hospital are more likely to receive their entire course of treatment at the same place. Conversely, continuity and efficiency of care can be both mined in small centers. Of note, Barzi et al. showed a significant impact of being treated at more than 1 facility. This was true specifically for lower VGs (4).

Even if clearly presented and thought-provoking, the study has some limitations. The NCDB is an essential source of standardized data for cancer surveillance providing standardized data regarding patients, hospitals, and therapies (18). However, NCDB data do not allow to calculate cancer-specific survival (CSS). Given the excellent life expectancy of patients diagnosed with localized PCa, the median OS was not reached after a median follow-up of 5 years. Since almost $100 \%$ of men who have regional PCa will survive more than 5 years after diagnosis, OS may be considered not a valid CSS surrogate in this population (19). In this regard, it is noteworthy that more than $70 \%$ of patients in the study had low or intermediate-risk PCa.

Therefore, most of the deaths reported in the first 5 -year after RP are very likely to be due to reasons other than cancer (19). In addition, survival estimates may be further biased by differences in baseline characteristics between populations treated at different VG hospitals as shown in the supporting table 1 (4). Compared to higher volume facility, hospitals below the median have a greater proportion of Black and Hispanic patients. Differences in socioeconomic status exist, with patients referring to lower volume hospitals having lower income and education. These factors have been demonstrated to influence quality of care and to be independently associated with worse survival after RP (20-23). Therefore, the gap in OS between FAC 
and FASC groups could be partly due to these differences. Whether baseline characteristics are significantly different or not is an essential exploratory analysis not undertaken here.

Barzi analyzed also the appropriateness of adjuvant therapies after prostatectomy. We would like to point out that in $30 \%$ of cases adjuvant treatment was indicated but not given (4). The proportion of this issue is similar within VGs, as well as, in FAC vs. FASC. This could be explained by the general belief that RP is curative.

To conclude, the authors made a remarkable effort to analyze the impact of volume on patients' survival, that is an under-studied outcome. They used one of the largest cohorts available in literature. Notwithstanding the retrospective nature of the study, Barzi et al. examined the hospital caseload from a new point of view, giving a significant contribution in order to identify the causes of the volume outcome relationship.

However, given the long-term survival rates of the PCa, the choice of OS with a median follow-up of 5 years reduce the strength of the findings. We believe future analyses with a longer follow-up time could provide further insights in the oncological outcome and hospital/surgical volume relationship.

\section{Acknowledgments}

Funding: None.

\section{Footnote}

Conflicts of Interest: All authors have completed the ICMJE uniform disclosure form (available at http://dx.doi. org/10.21037/gs.2020.01.08). The authors have no conflicts of interest to declare.

Ethical Statement: The authors are accountable for all aspects of the work in ensuring that questions related to the accuracy or integrity of any part of the work are appropriately investigated and resolved.

Open Access Statement: This is an Open Access article distributed in accordance with the Creative Commons Attribution-NonCommercial-NoDerivs 4.0 International License (CC BY-NC-ND 4.0), which permits the noncommercial replication and distribution of the article with the strict proviso that no changes or edits are made and the original work is properly cited (including links to both the formal publication through the relevant DOI and the license). See: https://creativecommons.org/licenses/by-nc-nd/4.0/.

\section{References}

1. Luft HS, Bunker JP, Enthoven AC. Should operations be regionalized? The empirical relation between surgical volume and mortality. N Engl J Med 1979;301:1364-9.

2. Schrag D, Panageas KS, Riedel E, et al. Hospital and surgeon procedure volume as predictors of outcome following rectal cancer resection. Ann Surg 2002;236:583-92.

3. Morgan TM, Barocas DA, Keegan KA, et al. Volume outcomes of cystectomy--is it the surgeon or the setting? J Urol 2012;188:2139-44.

4. Barzi A, Lara PN Jr, Tsao-Wei D, et al. Influence of the facility caseload on the subsequent survival of men with localized prostate cancer undergoing radical prostatectomy. Cancer 2019;125:3853-63.

5. Fujii MH, Hodges AC, Russell RL, et al. Post-discharge opioid prescribing and use after common surgical procedure. J Am Coll Surg 2018;226:1004-12.

6. Leow JJ, Leong EK, Serrell EC, et al. Systematic review of the volume-outcome relationship for radical prostatectomy. Eur Urol Focus 2018;4:775-89.

7. Ellison LM, Trock BJ, Poe NR, et al. The effect of hospital volume on cancer control after radical prostatectomy. J Urol 2005;173:2094-8.

8. Hu JC, Wang Q, Pashos CL, et al. Utilization and outcomes of minimally invasive radical prostatectomy. J Clin Oncol 2008;26:2278-84.

9. Eastham JA, Kattan MW, Riedel E, et al. Variations among individual surgeons in the rate of positive surgical margins in radical prostatectomy specimens. J Urol 2003;170:2292-5.

10. Evans SM, Millar JL, Frydenberg M, et al. Positive surgical margins: rate, contributing factors and impact on further treatment: findings from the Prostate Cancer Registry. BJU Int 2014;114:680-90.

11. Vickers AJ, Bianco FJ, Serio AM, et al. The surgical learning curve for prostate cancer control after radical prostatectomy. J Natl Cancer Inst 2007;99:1171-7.

12. Lawrentschuk N, Evans A, Srigley J, et al. Surgical margin status among men with organ-confined (pT2) prostate cancer: a population-based study. Can Urol Assoc J 2011;5:161-6.

13. Hollenbeck BK, Dunn RL, Miller DC, et al. Volumebased referral for cancer surgery: informing the debate. J Clin Oncol 2007;25:91-6. 
14. Gilbert SM, Dunn RL, Miller DC, et al. Mortality after urologic cancer surgery: impact of non-index case volume. Urology 2008;71:906-10.

15. Ellison LM, Heaney JA, Birkmeyer JD. The effect of hospital volume on mortality and resource use after radical prostatectomy. J Urol 2000;163:867-9.

16. Yao SL, Lu-Yao G. Population-based study of relationships between hospital volume of prostatectomies, patient outcomes, and length of hospital stay. J Natl Cancer Inst 1999;91:1950-6.

17. Konety BR, Allareddy V, Modak S, et al. Mortality after major surgery for urologic cancers in specialized urology hospitals: are they any better? J Clin Oncol 2006;24:2006-12.

18. Cole AP, Friedlander DF, Trinh QD. Secondary data sources for health services research in urologic oncology. Urol Oncol 2018;36:165-73.

19. Neal DE, Metcalfe C, Donovan JL, et al. Ten-year mortality, disease progression, and treatment-related

Cite this article as: Paciotti M, Fasulo V, Lughezzani G. The relationship between hospital volume and outcomes of radical prostatectomy: a new perspective on an old story. Gland Surg 2020;9(4):1072-1075. doi: 10.21037/gs.2020.01.08 side effects in men with localised prostate cancer from the Protec'T randomised controlled trial according to treatment received. Eur Urol 2020;77:320-30

20. Velasquez MC, Chinea FM, Kwon D, et al. The influence of ethnic heterogeneity on prostate cancer mortality after radical prostatectomy in Hispanic or Latino men: a population-based analysis. Urology 2018;117:108-14.

21. Gray PJ, Lin CC, Cooperberg MR, et al. Temporal trends and the impact of race, insurance, and socioeconomic status in the management of localized prostate cancer. Eur Urol 2017;71:729-37.

22. Sukumar S, Ravi P, Sood A, et al. Racial disparities in operative outcomes after major cancer surgery in the United States. World J Surg 2015;39:634-43.

23. Kim SP, Boorjian SA, Shah ND, et al. Disparities in access to hospitals with robotic surgery for patients with prostate cancer undergoing radical prostatectomy. J Urol 2013;189:514-20. 